\title{
Clinical Practice Guideline Executive Summary: Labor After Cesarean/Planned Vaginal Birth After Cesarean
}

\author{
Valerie J. King, MD, MPH, FAAFP \\ Patricia L. Fontaine, MD, MS, \\ FAAFP'
}

Lesley A. Atwood, MD, FAAFP

Elizabeth Powers, $M D^{4}$

Lawrence Leeman, $M D, M P H^{5}$

Jeffrey L. Ecker, MD ${ }^{6}$

Melissa D. Avery, PbD, CNM,

FACNM, FAAN ${ }^{7}$

Carol Sakala, $\mathrm{PbD}, \mathrm{MSPH}^{8}$

Doug Campos-Outcalt, MD, MPA ${ }^{9}$

Michelle Jeffcott-Pera, $M A^{10}$

Bellinda Schoof, MHA, CPHQ ${ }^{10}$

'Department of Family Medicine, Oregon Health \& Science University, Portland, Oregon

${ }^{2}$ HealthPartners Institute for Education and Research, Bloomington, Minnesota

${ }^{3}$ Department of Family Medicine, University of Minnesota, Hastings, Minnesota

${ }^{4}$ Winding Waters Clinic, PC, Enterprise, Oregon

${ }^{5}$ Family and Community Medicine, Obstetrics and Gynecology, University of New Mexico School of Medicine, Albuquerque, New Mexico

${ }^{6}$ Obstetrics, Gynecology and Reproductive Biology, Massachusetts General Hospital, Harvard Medical School, Boston, Massachusetts

${ }^{7}$ Midwifery, School of Nursing, University of Minnesota, Hastings, Minnesota

${ }^{8}$ Childbirth Connection, New York, New York

${ }^{9}$ Mercy Care Plan, Phoenix, Arizona

${ }^{10}$ American Academy of Family Physicians, Leawood, Kansas

Conflicts of interest: authors report none.

\section{CORRESPONDING AUTHOR}

Bellinda Schoof, MHA, CPHQ

Director, Health of the Public and Science American Academy of Family Physicians 11400 Tomahawk Creek Pkwy

Leawood, KS 66211

bschoof@aafp.org
Ann Fam Med 2015;13:80-81. doi: 10.1370/afm.1738.

C esarean deliveries are a common surgical procedure in the United States, accounting for 1 in 3 US births. The primary purpose of this guideline is to provide clinicians with evidence to guide planning for labor and vaginal birth after cesarean (LAC/VBAC). A multidisciplinary guideline development group representing family medicine, epidemiology, obstetrics, midwifery, and consumer advocacy used a high quality systematic review by the Agency for Healthcare Research and Quality (AHRQ) as the primary evidence source. The evidence report was updated to include research published through September 2012 with an additional key question on facilities and resources needed for LAC/VBAC. The guideline development group developed recommendations using a modified Grading of Recommendations, Assessment, Development, and Evaluation (GRADE) approach. The panel recommended that an individualized assessment of risks and benefits be discussed with pregnant women with a history of 1 or more prior cesarean births who are deciding between a planned LAC/ $\mathrm{VBAC}$ and a repeat cesarean birth. A planned LAC/VBAC is an appropriate option for most women with a history of prior cesarean birth. Increased access to providers and facilities capable of managing LAC/VBAC are required to reduce the US cesarean rate and associated maternal morbidity while increasing choice for childbearing women and their families.

\section{KEY EVIDENCE-BASED RECOMMENDATIONS}

- The AAFP recommends that clinicians counsel, encourage, and facilitate planned vaginal birth after cesarean (PVBAC) so that women can make informed decisions. If PVBAC is not locally available, then women desiring it should be offered referral to a facility or clinician who can offer the service. (Quality of Evidence: Moderate)

- The AAFP strongly recommends that clinicians inform women who have had a prior vaginal birth that they have a high likelihood of vaginal birth after cesarean. Unless there are specific contraindications to a vaginal birth, these women should be encouraged to plan LAC/VBAC and should be offered referral to clinicians and facilities capable of providing this service if not available locally. (Quality of Evidence: High)

- The AAFP recommends that induction of labor after cesarean is appropriate for women who have a medical indication for induction of labor and who are planning a LAC/VBAC. Misoprostol should not be used for cervical preparation or induction of labor after cesarean in the third trimester of pregnancy for women with a prior cesarean birth. (Quality of Evidence: Low to Moderate)

\section{Good Practice Points}

- Clinicians should discuss indications for and circumstances surrounding the prior cesarean birth(s).

- At time of labor and presentation to the hospital, the plan for labor and vaginal birth should be reassessed considering factors on admission that 
may affect the risks of labor and likelihood of vaginal birth. Any changes in status should be discussed during labor.

- Patients should be informed of the specific shortterm benefits and harms of planned LAC/VBAC for the patient and fetus/infant. Current evidence supports differences in rare outcomes with LAC/VBAC, including lower maternal mortality (Quality of Evidence: High) but more chance of uterine rupture and higher perinatal mortality. (Quality of Evidence: Moderate)

- Patients should be informed of the long-term benefits and harms of planned labor and vaginal birth after cesarean. Compared with vaginal birth after cesarean, a repeat cesarean delivery increases risks during subsequent pregnancies of abnormal placentation (Quality of Evidence: Moderate), hysterectomy (Quality of Evidence: Moderate), and surgical complications (Quality of Evidence: Low). Care should be individualized regarding lifetime plans for childbearing.
- All women desiring planned LAC/VBAC should be counseled about the capabilities of their specific delivery setting and women at high risk for complications should be referred as necessary to facilities with capabilities to effectively treat problems as they develop.

- Hospitals should have guidelines to promote access to LAC/VBAC and actively monitor and improve quality of care for women who choose labor after cesarean.

To read or post commentaries in response to this article, see it online at http://www.annfammed.org/content/13/1/80.

Submitted August 15, 2014; submitted, revised, August 15, 2014; accepted September 10, 2014.

Key words: vaginal birth after Cesarean; Cesarean section; VBAC

Supplementary materials: http://www.aafp.org/patient-care/clinicalrecommendations/all/vaginal-birth-after-cesarean.html.

Funding support: Financial support for this guideline comes exclusively from the operating budget of the American Academy of Family Physicians.

\section{CHANGE-OF-ADDRESS FORM FAMNILY MEDICINE}

Please complete this form and mail to the following address or fax to Annals Circulation at 913-906-6080:

Annals of Family Medicine, Circulation Department, 11400 Tomahawk Creek Pkwy, Leawood, KS 66211-2680

Check if member of sponsoring organization:

$\begin{array}{ll}\square \text { AAFP } & \square \text { ABFM } \square \text { STFM } \square \text { ADFM } \\ \square \text { AFMRD } \square \text { NAPCRG } \square \text { CFPC }\end{array}$

ID number from label on your journal cover

OLD Information (Please print.)

\begin{tabular}{lc}
\hline Name \\
\hline Company (if applicable) \\
\hline Address (Street plus Apt or Ste) \\
\hline City \\
\hline Country \\
\hline Telephone \\
\hline E-Mail & Faxtal Code (9-digit ZIP for US) \\
\hline
\end{tabular}

NEW Information (Please print.)

\begin{tabular}{ll}
\hline Name \\
\hline Company (if applicable) \\
\hline Address (Street plus Apt or Ste) \\
\hline City & Postal Code (9-digit ZIP for US) \\
\hline Country & Fax \\
\hline Telephone & \\
\hline E-Mail &
\end{tabular}

